\title{
PET/CT for Head and Neck Squamous Cell Cancer-Uses and Updates for Radiologists
}

\author{
Jorge D. Oldan • David S. Yoo $\cdot$ Walter T. Lee • \\ Jenny K. Hoang
}

Published online: 20 March 2014

(C) Springer Science+Business Media New York 2014

\begin{abstract}
Positron emission tomography-computed tomography (PET/CT) is commonly used in the staging and restaging of head and neck squamous cell carcinoma (HNSCC). In this review paper we discuss the scenarios in which PET/CT that can affect the management of HNSCC patients. These include locating a carcinoma of unknown primary, staging the clinically node-negative neck, pretreatment staging of advanced disease, and post-treatment evaluation. We summarize the evidence for these uses on the basis of recent literature and also discuss emerging applications of PET/CT for HNSCC. These are topics that radiologists commonly encounter in clinical practice and on head and neck tumor boards.
\end{abstract}

This article is part of the Topical Collection on Advanced Imaging of the Head and Neck Region.

J. D. Oldan

DUMC 3949, Division of Nuclear Medicine, Department of

Radiology, Duke University Medical Center, Durham, NC

27710, USA

e-mail: jorge.oldan@dm.duke.edu

D. S. Yoo

DUMC 3085, Department of Radiation Oncology, Duke University Medical Center, Durham, NC 27710, USA

e-mail: david.yoo@dm.duke.edu

\section{W. T. Lee}

DUMC 3805, Department of Otolaryngology, Duke University Medical Center, Durham, NC 27710, USA

e-mail: walter.lee@dm.duke.edu

J. K. Hoang ( $\square)$

DUMC 3808, Division of Neuroradiology, Department of Radiology, and Department of Radiation Oncology, Duke University Medical Center, Durham, NC 27710, USA

e-mail: jennykh@gmail.com
Keywords PET/CT $\cdot$ Head and neck $\cdot$ Squamous cell carcinoma $\cdot$ Review $\cdot$ Staging $\cdot$ Restaging

\section{Introduction}

PET/CT (positron emission tomography/computed tomography) is a widely used modality in oncology for a variety of cancers. In the clinic, PET imaging is performed with ${ }^{18} \mathrm{~F}$-fluorodeoxyglucose (FDG), a glucose analog which is taken up by hypermetabolic cancer cells. As a marker of metabolic activity, FDG-PET may detect changes earlier than anatomy-based imaging modalities, for example CT, MRI, or ultrasound. PET/CT can also aid differentiation of residual tumor from post-treatment changes $[1 \bullet, 2]$. These advantages have made PET/CT particularly useful in the staging, post-treatment evaluation, and surveillance of patients with head and neck cancer squamous cell cancer (HNSCC).

In this article, we describe common uses of PET/CT for HNSCC and summarize the evidence for these uses on the basis of recent literature. We also discuss emerging applications of PET/CT for HNSCC that may become important in the future. These are topics that radiologists commonly encounter in clinical practice and on head and neck tumor boards.

Clinical Roles of PET/CT — Why do We Need to Know? How Good is PET/CT?

One of the first studies on PET/CT for HNSCC was published in 1992 [3]. Since then, clinical use of PET/CT has expanded, and the number of published papers has multiplied. In the current cost-conscious era of evidence-based medicine, it is important for the radiologist and ordering 
Fig. 1 56-year-old man with cervical nodal squamous cell metastases and unknown primary tumor. He presented with an enlarging right neck mass corresponding to level II/ III lymph nodes on CT. Biopsy of the lymph nodes revealed squamous cell carcinoma. Initial $\mathrm{CT}$ and clinical examination did not identify a primary tumor so PET/CT was performed. Axial CT (a), PET (b) and fused (c) PET/CT images of the neck reveal asymmetric uptake by the palatine tonsils. Right tonsil (arrow) had SUVmax of 10.7 compared with 6.4 for the left tonsil, but was not enlarged. At surgery, a firm, $<1 \mathrm{~cm}$ friable mass on the right inferior tonsillar pole was seen and biopsied, revealing squamous cell carcinoma

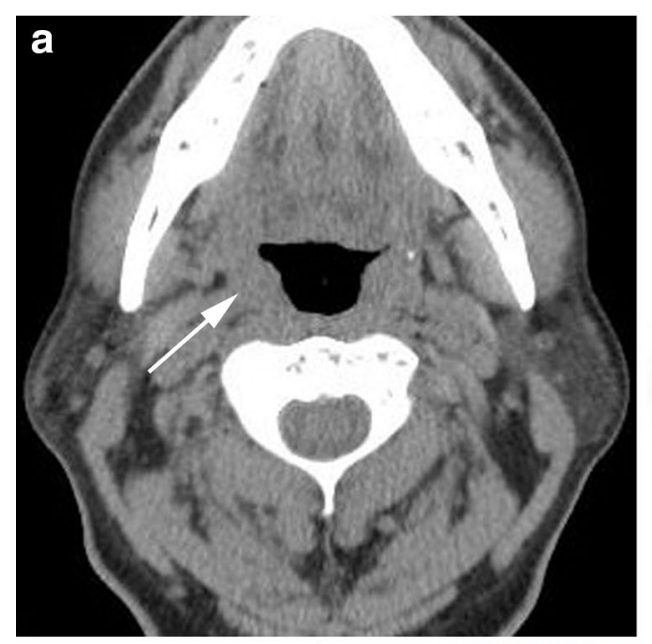

b

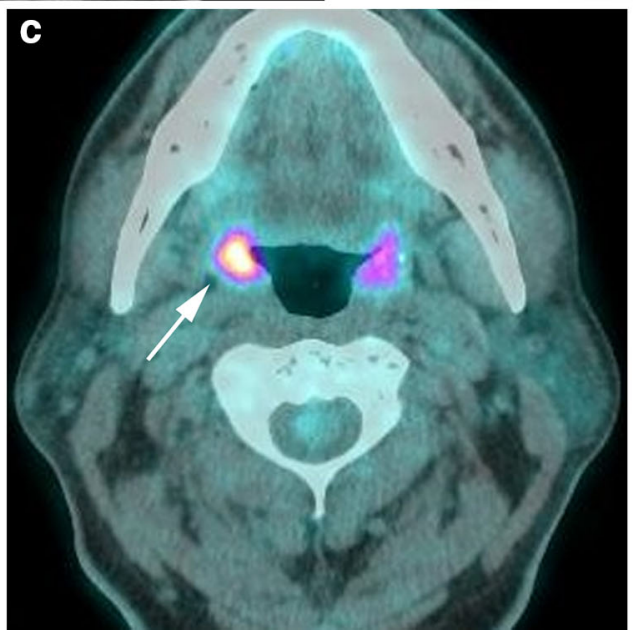

clinician to understand both the strengths and limitations of $\mathrm{PET} / \mathrm{CT}$. This section describes four specific scenarios in which PET/CT findings can affect the management of HNSCC patients. For each scenario, we provide an update on the evidence for or against the use of PET/CT.

\section{Carcinoma of Unknown Primary}

Carcinoma of unknown primary (CUP) is the clinical situation in which patients present with cervical nodal squamous cell carcinoma metastases without an identifiable primary tumor (Fig. 1). It is important to distinguish CUP, or occult primary cancer, from cases in which the primary is not seen on imaging because the tumor is small, superficial in location, or obscured by a CT or MRI artifact created by dental hardware. Accurate determination of the primary tumor site enables use of more confined radiation fields, minimizing treatment morbidity. Thus, before being labeled as CUP, an extensive diagnostic workup is performed with directed endoscopic biopsies of likely sites of origin and may include tonsillectomy. PET/CT before endoscopy can help detect small primary tumors not otherwise seen on imaging and thus help to direct biopsies, reduce operative times, and avoid more invasive procedures.

A recent meta-analysis by Zhu et al. evaluated the performance of PET/CT for detection of primary sites among patients with cervical nodal metastases of unknown origin [4•]. They analyzed seven papers which included results for 246 patients and found PET/CT to have excellent diagnostic performance for detection of primary tumors: combined sensitivity was $97 \%$ and specificity was $68 \%$. Notably, tumor detection was only $44 \%$, reflecting that many cases were true CUP with no primary tumor found even with extensive workup. This point was also emphasized in the 2013 Guidelines of the Ontario Head and Neck Disease Site Group [5••], who recommended PET/CT for workup of nodal metastases without primary origin, but noted that a primary tumor site may not always be found.

\section{Pretreatment Staging for Clinical NO Disease}

Patients with clinical N0 disease are those with known primary HNSCC, but no clinically detectable nodal 


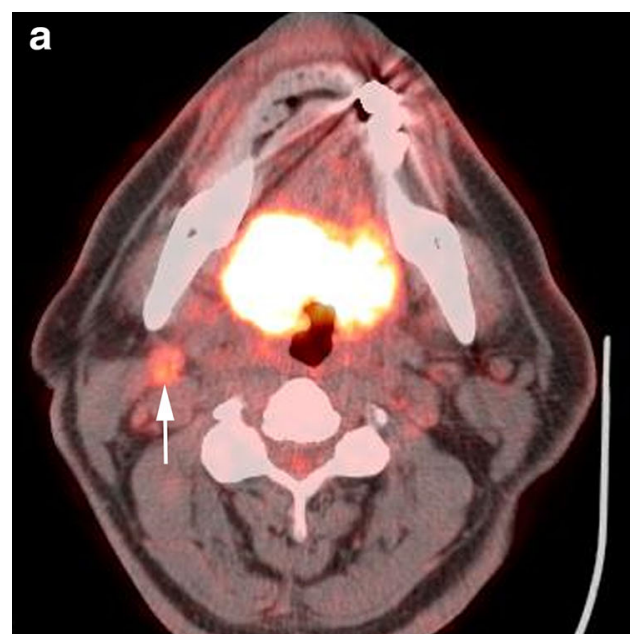

Fig. 2 69-year-old man with a large base of tongue squamous cell carcinoma and clinical N0 disease. He presented with increasing tongue pain, dysphagia, and odynophagia, and had no palpable nodes on neck examination. Neck CT revealed bilateral base of tongue mass

metastases (Fig. 2). These patients have a better prognosis than those with nodal disease. However, early nodal metastases may be occult-not clinically palpable or observed on CT or MRI. The risk of harboring nodal disease is based on such clinical factors as tumor stage, tumor location, histologic characteristics, and historical data from the surgical literature. Traditionally, patients with at least an estimated 15-20\% risk of occult metastases undergo some form of elective neck treatment [6].

These percentages suggest that most clinical N0 patients undergo potentially unnecessary therapy, with the accompanying healthcare costs and treatment morbidity. It is well accepted that a pre-treatment PET/CT that positively identifies previously occult lymph nodes confirms the need for targeted therapy to the neck (Fig. 2). However, it is more controversial whether a negative PET/CT precludes the need for elective nodal dissection or radiotherapy.

The best evidence to date addressing whether PET/CT can effectively exclude occult disease and prevent elective nodal treatment comes from a meta-analysis of 32 studies (1235 HNSCC patients) assessing the diagnostic accuracy of PET for detection of nodal metastases [6]. Kyzas et al. performed a subgroup analysis for clinical N0 disease and found the specificity of PET was $87 \%$, but with sensitivity of only $50 \%$. A more recent meta-analysis by Liao et al. [7••] compared the performance of PET with that of other modalities without functional imaging (ultrasound, CT, or MRI) for clinical N0 disease. From 11 studies with 587 patients, combined specificity for PET was $87 \%$ and sensitivity was $66 \%$, which was not significantly different from those for ultrasound, CT, and MRI.

A multicenter clinical trial led by the American College of Radiology Imaging Network (ACRIN) is currently

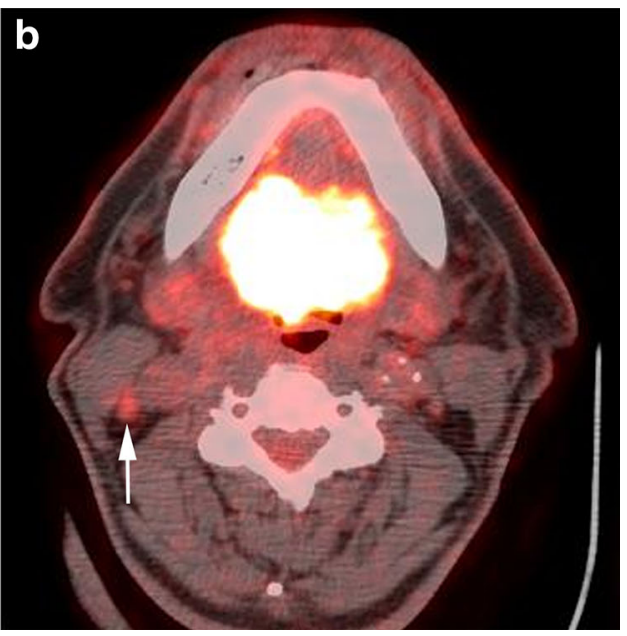

but no suspicious lymph nodes. A PET/CT was performed to identify occult nodal metastases. (a) and (b) Fused PET/CT images show the base of tongue mass and two hypermetabolic right level IIA nodes (arrows) indicative of metastatic disease

evaluating this question prospectively. Their objective is to determine the negative predictive value of PET for patients with clinically N0 neck. Until these results are available, the current literature suggest PET/CT is suboptimum for deciding whether to avoid elective nodal therapy for patients with clinical No disease: there is no evidence that PET/CT is better than anatomical imaging alone and PET/ CT will still miss up to half of patients with clinically occult metastases.

\section{Pretreatment Staging in Advanced Disease}

Accurate nodal staging is also important for patients with clinically detectable nodal metastases. A difficult scenario is when a patient has unilateral metastatic cervical nodes, but has high risk of clinically occult contralateral node involvement. Such patients include those with tumors centered at the midline or which invade the midline, or simply patients with a large burden of ipsilateral nodal disease (Fig. 3). These patients may have elective bilateral nodal treatment despite a clinically negative contralateral neck. As with the scenario for clinical NO disease, some propose that a negative PET/CT may help with the decision to limit treatment to the ipsilateral neck or selective nodal treatment.

For nodal staging in general, individual studies show that PET/CT is better than CT and/or MRI alone in the strict sense of finding more malignant nodes. A study by Nguyen of 71 patients found $94 \%$ sensitivity for PET/CT versus $79 \%$ for MR or CT alone [8]. However, in studies that focus on the ipsilateral and contralateral cervical nodes, the performance of PET is lower for contralateral nodes. Kim et al. [9] compared PET/CT with MR or CT for 
Fig. 3 63-year-old man with a soft-palate squamous cell carcinoma and occult contralateral nodal metastasis. (a) Axial CT image shows a left level IIA node to be mildly enlarged and enhancing (arrow). There were no suspicious right-sided lymph nodes. Despite the right neck being normal on clinical examination and CT, a PET/CT was performed because the tumor was midline which is associated with an increased risk of bilateral metastases. (b) PET and (c) fused PET/CT images show both level IIA nodes (arrows) have increased FDG uptake (arrows). The stage of the patient's disease increased from $\mathrm{N} 1$ (one node $<3 \mathrm{~cm}$ ) to N2c (bilateral nodal disease)
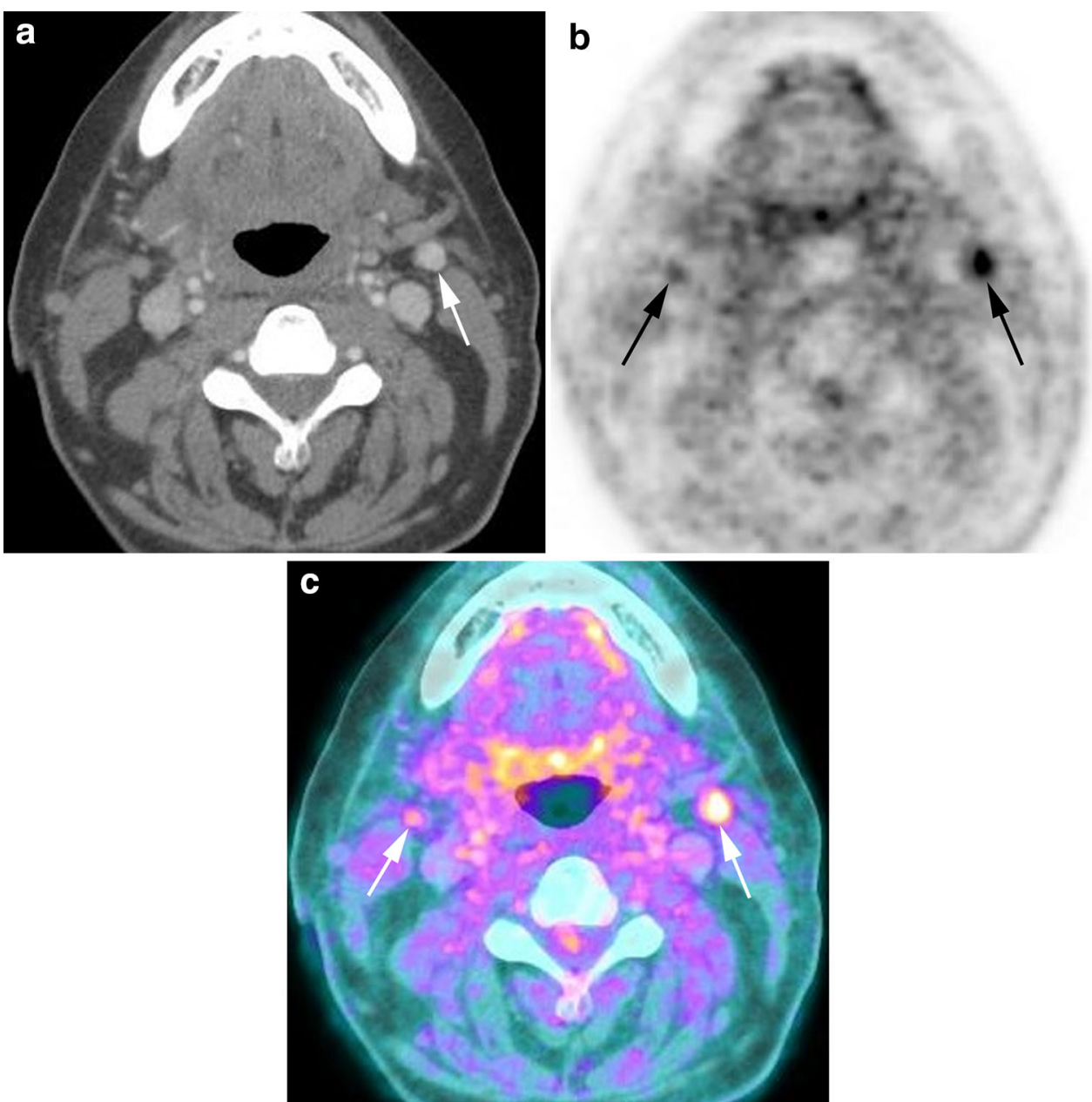

determination of the laterality of nodal disease for 114 patients. For ipsilateral metastases, they reported higher sensitivities of $88 \%$ for PET versus $70 \%$ for CT/MRI. For contralateral disease, the sensitivity of PET and CT/MRI was 52 and $36 \%$, respectively. A more recent study of PET/CT among 61 patients found similar sensitivities of $80 \%$ for ipsilateral disease and $65 \%$ for contralateral disease [10]. Both studies concluded that PET/CT could not be used to avoid contralateral neck surgery or radiotherapy for high-risk patients. Interestingly, the sensitivity of PET for contralateral nodal disease is similar to the sensitivity for occult metastases when there is clinically NO disease, which emphasizes the limitation of PET in detecting small metastatic nodal deposits.

\section{Post-Treatment Evaluation for Residual Disease}

One of the most important and well-established uses of PET/CT in HNSCC is post-treatment evaluation after curative-intent chemoradiation (Fig. 4). After chemoradiation therapy, the two potential outcomes are complete response or residual disease. Patients with complete response will receive no further treatment whereas patients with residual disease require salvage surgery at the suboptimally treated tumor sites. One of the challenges after treatment is differentiating between residual tumor and post-treatment changes on CT or MRI, because some patients with complete response may still have residual nodal tissue with no viable tumor (Fig. 4). For these patients a negative PET/CT may support the decision to closely observe the patient rather than perform unnecessary surgery.

The largest meta-analysis evaluating the diagnostic performance of post-treatment PET/CT in HNSCC was that by Gupta et al. [11••] which included 51 prospective and retrospective studies of 2,335 patients. The combined specificity $(88 \%)$ and negative predictive value $(95 \%)$ were excellent and the same for both primary tumor and nodal metastases. These results support the practice at many institutions that a negative PET scan could be used to avoid salvage surgery. However, a limitation of PET/CT for post-treatment evaluation is seen in the setting of a positive PET scan. Gupta et al. [11••] found low positive predictive values for the primary tumor $(59 \%)$ and nodal 
Fig. 4 48-year-old man with residual disease after curativeintent chemoradiation for T4N2bM0 left palatine tonsil squamous cell carcinoma. (a) Pretreatment fused PET/CT image shows a large left tonsillar mass extending into the base of the tongue and oral tongue (arrowheads), and an enlarged metabolically active left level IIA node (arrow). He had persistent left tongue pain and trismus 11 weeks after completion of chemoradiation. A PET/CT scan performed shortly afterward. (b) Posttreatment fused PET/CT image shows a persistent mass with metabolic activity in the left tonsil and tongue base (arrowheads). This is highly suggestive of residual disease at the primary site and was confirmed by biopsy. (c) Posttreatment fused PET/CT image shows no metabolic activity in the remaining left level IIA node lymph node (arrow). This is consistent with the response for the nodal metastasis
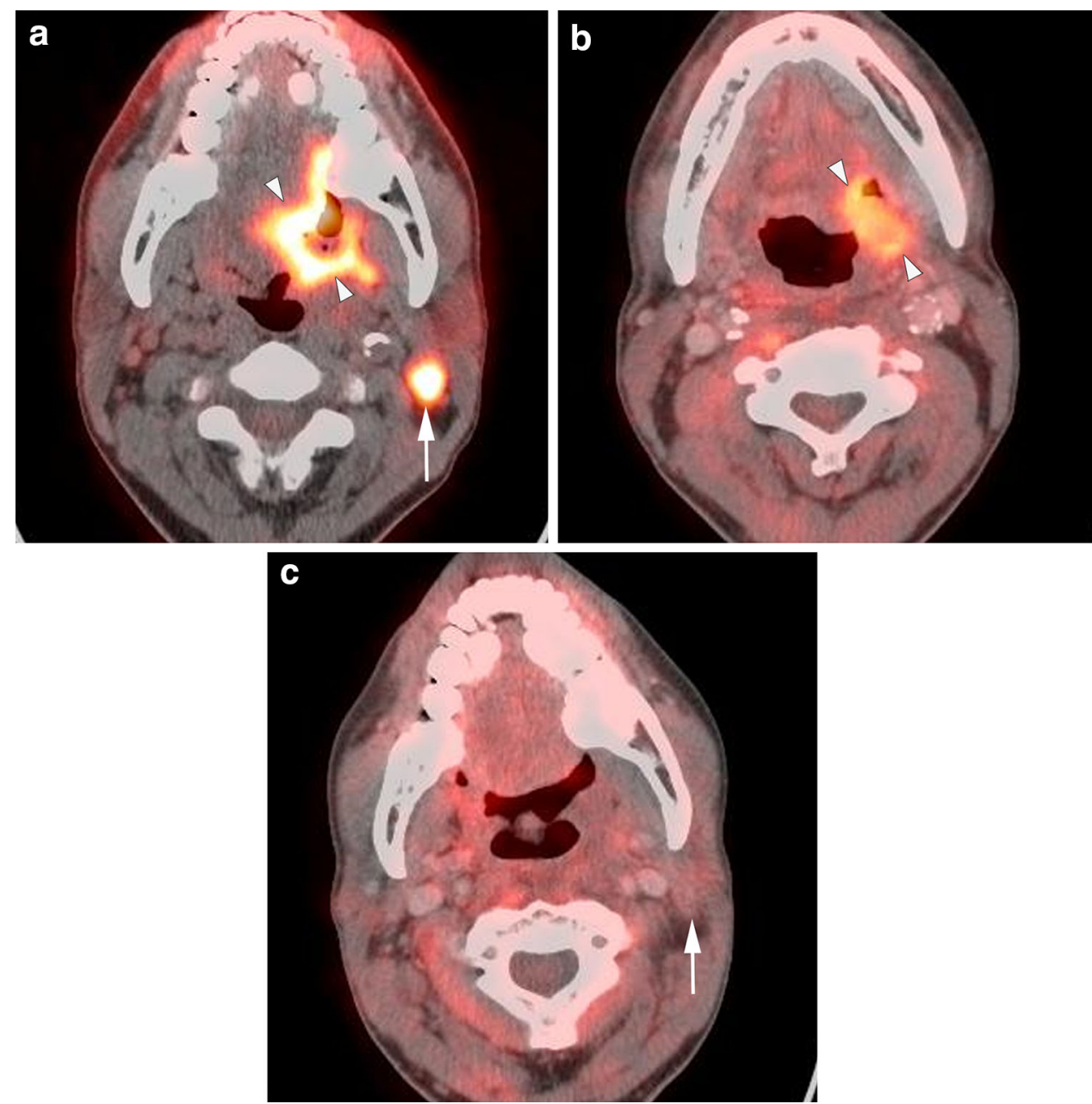

disease (52\%), which indicate the tracer, FDG, is not tumor-specific. Metabolic uptake can indicate tumor, but can also be found with treatment change or inflammation.

The timing of PET/CT can help to reduce false-positive results; Gupta et al. obtained fewer false-positive results for nodes in studies timed at or greater than 12 weeks (5.7\%) after completion of chemoradiation compared with before 12 weeks $(14.9 \%)$. A recent single-center study reported similar results. For 311 patients, the accuracy for scans performed within two months after the completion of treatment was $69 \%$ as opposed to $93 \%$ for scans after 2 months [12].

Some centers also advocate performing a second posttreatment PET/CT scan within six months of chemoradiation. A large retrospective study of 512 patients examined the value of one negative PET/CT compared with two negative PET/CT scans. After a minimum 12-month follow-up period, they found one negative PET/CT had $91 \%$ negative predictive value (NPV) for malignancy, but two negative PET/CTs performed within six months of each other had $98 \%$ NPV [1•]. The implication is that a single post-treatment PET/CT may not be adequate to eliminate the need for further radiological surveillance, but clinicians could rely on clinical surveillance after a second PET/CT.

Future Directions-Trends and Developments

\section{Evaluating Early Treatment Response}

One topic of active interest is evaluation of response to therapy by using PET/CT during treatment. This may entail imaging within the first few weeks of an eight-week course of concurrent chemoradiation or during induction chemotherapy which is performed before chemoradiation. Early evaluation with PET/CT at these times could enable detection of favorable or unfavorable metabolic changes before anatomic changes are evident and, thus, early identification of non-responders who may be candidates for adaptive treatment strategies, new molecularly-targeted therapy, or primary surgery.

The results of the studies are mixed for imaging with PET/CT during the first few weeks of chemoradiation 
(intra-treatment imaging). Hentschel et al. [13] performed PET scans for 37 patients several times during radiation for HNSCC and found imaging at 1-2 weeks to be the best time for identifying patients with response, as indicated by a rapid drop in FDG uptake. Castaldi et al. [14] performed imaging at two weeks and found poor correlation between early PET changes and clinical outcome. Other studies have imaged later during radiotherapy (four weeks) and found intra-treatment PET to be useful if there was dramatic response (high specificity), but persistent metabolic activity on the intra-treatment PET did not identify patients that would have residual disease or poorer prognosis (low sensitivity) [15].

Induction (or neoadjuvant) chemotherapy is used in some centers for patients with inoperable locally advanced tumors. In the last decade several studies have shown that PET/CT can be used to identify patients who are more likely to respond to concurrent chemoradiation after induction chemotherapy $[16,17]$. In the most recent study, Abgral et al. [18] performed PET/CT twice during three cycles of induction chemotherapy for 15 patients with HNSCC and reported significantly better event-free survival for patients for whom reduction in SUVmax was greater than 15-25\%.

One issue in evaluation of early treatment response is the feasibility of distinguishing small changes in metabolic activity reflecting tumor response from baseline variation in tumor metabolic activity. Hoang et al. quantified the baseline variability and compared the changes in SUVmax with intra-treatment change. They found that baseline variability in SUVmax in nodal metastases could vary by as much as $10 \%$ even if the imaging was performed on the same scanner, but the variability was still less than intratreatment change at 1-2 weeks [19].

\section{Novel PET Radiopharmaceuticals}

PET is often seen as being synonymous with ${ }^{18} \mathrm{~F}-\mathrm{FDG}$, but a variety of other radiopharmaceuticals have been evaluated for imaging HNSCC. Although these novel PET tracers target tumor more specifically than does FDG, they currently have a number of disadvantages that have limited clinical adoption (Table 1).

The most promising alternative tracer is ${ }^{18} \mathrm{~F}$-fluoromisonidazole (FMISO), which is a molecular agent for tumor hypoxia. Because hypoxic cells are more resistant to the cytotoxic effects of radiation, hypoxia is associated with poor outcome in HNSCC [20]. Current obstacles to clinical use are long examination protocols ( $4 \mathrm{~h}$ post-injection) and a "ceiling effect" in which hypoxia is underestimated below a threshold [21, 22]. However, it has been shown to have some promise in evaluation of intra-treatment and post-treatment response and has been used to help target dose painting and dose escalation procedures for radiotherapy [23-32].

${ }^{18}$ F-fluoroazomycin arabinoside (FAZA), another hypoxic agent, has recently been evaluated in a study with pretreatment and intra-treatment time points. The investigators observed significantly lower disease-free survival among patients with hypoxic tumors [33•]. There has also been interest in ${ }^{18} \mathrm{~F}$-fluorothymidine (FLT) for intra-treatment imaging. This is a DNA analog which tracks cell

Table 1 Novel tracers for head and neck squamous cell cancer

\begin{tabular}{|c|c|c|c|}
\hline Tracer & Pathway & Uses/advantages & Disadvantages compared with FDG PET \\
\hline${ }^{18} \mathrm{~F}-\mathrm{F}-\mathrm{MISO}$ & Hypoxia & $\begin{array}{l}\text { Detect hypoxia during radiotherapy [32] } \\
\text { Radiation planning }[27,29]\end{array}$ & Long imaging procedure [21] \\
\hline${ }^{18} \mathrm{~F}-\mathrm{HX}$,,${ }^{18} \mathrm{~F}-\mathrm{FAZA}$ & Hypoxia & May be faster than F-MISO $\left[33^{\bullet}, 37\right]$ & Still experimental \\
\hline $\begin{array}{l}{ }^{18} \text { F-fluorothymidine } \\
\text { (FLT) }\end{array}$ & $\begin{array}{l}\text { DNA synthesis } \\
\text { (thymidine } \\
\text { analog) }\end{array}$ & $\begin{array}{l}\text { More specific for cancer than FDG [38 } \\
\text { Possible uses in post-treatment assessment (detects } \\
\text { change earlier) [34] and as a prognostic indicator } \\
\text { [39] }\end{array}$ & $\begin{array}{l}\text { Less sensitive than FDG }\left[38^{\bullet}\right] \\
\text { Higher background uptake in the liver } \\
\text { and bone marrow }\left[38^{\bullet}\right]\end{array}$ \\
\hline $\begin{array}{l}{ }^{18} \mathrm{~F}- \\
\text { fluoroethyltyrosine } \\
\left({ }^{18} \mathrm{~F}-\mathrm{FET}\right)\end{array}$ & $\begin{array}{l}\text { Protein synthesis } \\
\text { (amino acid } \\
\text { analog) }\end{array}$ & More specific for cancer than FDG [40] & Less sensitive than FDG [40] \\
\hline $\begin{array}{l}{ }^{11} \mathrm{C} \text {-methionine }\left({ }^{11} \mathrm{C}-\right. \\
\text { MET })\end{array}$ & $\begin{array}{l}\text { Protein synthesis } \\
\text { (amino acid } \\
\text { analog) }\end{array}$ & $\begin{array}{l}\text { Has been used to predict effectiveness of carbon-ion } \\
\text { radiotherapy }[41,42]\end{array}$ & $\begin{array}{l}\text { Short half-life } \\
\text { Other applications not yet validated }\end{array}$ \\
\hline Choline $\left({ }^{18} \mathrm{~F}\right.$ or $\left.{ }^{11} \mathrm{C}\right)$ & $\begin{array}{l}\text { Cell proliferation } \\
\text { (membrane } \\
\text { synthesis) }\end{array}$ & $\begin{array}{l}\text { Similar to FDG; may be more useful in skull base } \\
\text { tumors [43] }\end{array}$ & $\begin{array}{l}\text { Not otherwise superior to FDG [43], } \\
\text { slightly less effective for recurrence } \\
{[43,44]}\end{array}$ \\
\hline${ }^{18}$ F-galacto-RGD & $\begin{array}{l}\text { Angiogenesis } \\
(\alpha \vee \beta 3 \text { receptor })\end{array}$ & Demonstrates receptor expression [45] & $\begin{array}{l}\text { Little validation for humans with head } \\
\text { and neck PET }\end{array}$ \\
\hline
\end{tabular}


proliferation. Hoshikawa et al. [34] observed earlier and greater reductions in SUV on FLT imaging than FDG in the intra-treatment period.

Obstacles to use include lack of access to tracers and reimbursement. Insurance companies do not currently reimburse for use of tracers other than FDG. In addition, even for research purposes, many of the tracers may be difficult to obtain, and tracers using radionuclides other than F-18 require use of an on-site cyclotron, because other commonly used radionuclides, for example $\mathrm{C}-11$, have very short half-lives.

\section{PET/MRI}

A technological advance causing substantial excitement is PET/MRI, in which a PET and an MRI scan are acquired together, either simultaneously or sequentially. MRI has advantages over CT in having greater contrast resolution, which is especially advantageous for evaluation of mucosal lesions and perineural disease. Although studies have shown combined PET and MRI to be superior to evaluation with MRI only, there are no proven differences between PET/CT and the more costly PET/MRI for HNSCC [35]. In a prospective study comparing PET/CT with PET/MRI for 17 patients with HNSCC, diagnostic capability was not significantly different [36].

\section{Conclusion}

In summary, PET has many useful applications in the diagnosis and treatment of HNSCC. Literature supports its utility for evaluation of carcinoma with unknown primaries and for post-treatment assessment of residual disease, but it currently still seems to be limited for detection of clinically occult nodal metastases. For determining early response during treatment, it remains more specific than sensitive, which is problematic because it is more important to identify non-responders to therapy. Because FDG is not tumor-specific, active research is being conducted to evaluate new PET tracers for early treatment response.

\section{Compliance with Ethics Guidelines}

Conflict of Interest JD Oldan declares no conflicts of interest. DS Yoo received payment from Oakstone for development of educational materials. WT Lee declares no conflicts of interest. JK Hoang declares no conflicts of interest.

Human and Animal Rights and Informed Consent This article does not contain any studies with human or animal subjects performed by any of the authors.

\section{References}

Papers of particular interest, published recently, have been highlights as:

- Of importance;

•- Of major importance

1. - McDermott M, Hughes M, Rath T, Johnson JT, Heron DE, Kubicek GJ, et al. Negative predictive value of surveillance PET/ $\mathrm{CT}$ in head and neck squamous cell cancer. AJNR Am J neuroradiol. 2013 Aug;34(8):1632-6. Large study of the predictive value of surveillance PET/CT. This study also suggests a possible role for two post-treatment PET/CT studies.

2. Dunsky KA, Wehrmann DJ, Osman MM, Thornberry BM, Varvares MA. PET-CT and the detection of the asymptomatic recurrence or second primary lesions in the treated head and neck cancer patient. Laryngoscope. 2013;123(9):2161-4.

3. Bailet JW, Abemayor E, Jabour BA, Hawkins RA, Ho C, Ward $\mathrm{PH}$. Positron emission tomography: a new, precise imaging modality for detection of primary head and neck tumors and assessment of cervical adenopathy. Laryngoscope. 1992;102(3):281-8.

4. - Zhu L, Wang N. 18F-fluorodeoxyglucose positron emission tomography-computed tomography as a diagnostic tool in patients with cervical nodal metastases of unknown primary site: a meta-analysis. Surg Oncol. 2013 Sep;22(3):190-4. Meta-analysis covering the case of carcinoma of unknown primary. This helps demonstrate the utility of PET/CT for this application.

5. •• Yoo J, Henderson S, Walker-Dilks C. Evidence-based guideline recommendations on the use of positron emission tomography imaging in head and neck cancer. Clin Oncol. 2013 Apr;25(4):e33-66. Evidence-based guidelines summarizing many different applications of PET/CT; this paper is a good guide to other recent literature on the subject.

6. Kyzas PA, Evangelou E, Denaxa-Kyza D, Ioannidis JP. 18Ffluorodeoxyglucose positron emission tomography to evaluate cervical node metastases in patients with head and neck squamous cell carcinoma: a meta-analysis. J Natl Cancer Inst. 2008;100(10):712-20.

7. • Liao LJ, Lo WC, Hsu WL, Wang CT, Lai MS. Detection of cervical lymph node metastasis in head and neck cancer patients with clinically N0 neck-a meta-analysis comparing different imaging modalities. BMC Cancer. 2012;12:236. Meta-analysis of studies of PET/CT for evaluation of the clinically NO neck; a good guide to the studies on this subject.

8. Nguyen A, Luginbuhl A, Cognetti D, Van Abel K, Bar-Ad V, Intenzo $\mathrm{C}$, et al. Effectiveness of PET/CT in the preoperative evaluation of neck disease. Laryngoscope. 2014;124(1):159-64.

9. Kim SY, Kim JS, Doo H, Lee H, Lee JH, Cho KJ, et al. Combined [18F]fluorodeoxyglucose positron emission tomography and computed tomography for detecting contralateral neck metastases in patients with head and neck squamous cell carcinoma. Oral Oncol. 2011;47(5):376-80.

10. Kastrinidis N, Kuhn FP, Hany TF, Ahmad N, Huber GF, Haerle SK. 18F-FDG-PET/CT for the assessment of the contralateral neck in patients with head and neck squamous cell carcinoma. Laryngoscope. 2013;123(5):1210-5.

11. • Gupta T, Master Z, Kannan S, Agarwal JP, Ghsoh-Laskar S, Rangarajan V, et al. Diagnostic performance of post-treatment FDG PET or FDG PET/CT imaging in head and neck cancer: a systematic review and meta-analysis. Eur J Nucl Med Mol Imaging. 2011 Nov;38(11):2083-95. Meta-analysis of posttreatment PET/CT; useful for its review of the literature, as well 
as its extensive analysis of test performance metrics. It also addresses the 12-week cutoff issue in its analysis.

12. Nakamura S, Toriihara A, Okochi K, Watanabe H, Shibuya H, Kurabayashi T. Optimal timing of post-treatment [18F]fluorodeoxyglucose-PET/CT for patients with head and neck malignancy. Nucl Med Commun. 2013;34(2):162-7.

13. Hentschel M, Appold S, Schreiber A, Abolmaali N, Abramyuk A, Dorr W, et al. Early FDG PET at 10 or 20 Gy under chemoradiotherapy is prognostic for locoregional control and overall survival in patients with head and neck cancer. Eur J Nucl Med Mol Imaging. 2011;38(7):1203-11.

14. Castaldi P, Rufini V, Bussu F, Micciche F, Dinapoli N, Autorino $\mathrm{R}$, et al. Can "early" and "late"18F-FDG PET-CT be used as prognostic factors for the clinical outcome of patients with locally advanced head and neck cancer treated with radio-chemotherapy? Radiother Oncol. 2012;103(1):63-8.

15. Ceulemans G, Voordeckers M, Farrag A, Verdries D, Storme G, Everaert H. Can 18-FDG-PET during radiotherapy replace posttherapy scanning for detection/demonstration of tumor response in head-and-neck cancer? Int J Radiat Oncol Biol Phys. 2011;81(4):938-42.

16. McCollum AD, Burrell SC, Haddad RI, Norris CM, Tishler RB, Case MA, et al. Positron emission tomography with 18F-fluorodeoxyglucose to predict pathologic response after induction chemotherapy and definitive chemoradiotherapy in head and neck cancer. Head Neck. 2004;26(10):890-6.

17. Yoon DH, Cho Y, Kim SY, Nam SY, Choi SH, Roh JL, et al. Usefulness of interim FDG-PET after induction chemotherapy in patients with locally advanced squamous cell carcinoma of the head and neck receiving sequential induction chemotherapy followed by concurrent chemoradiotherapy. Int J Radiat Oncol Biol Phys. 2011;81(1):118-25.

18. Abgral R, Le Roux PY, Keromnes N, Rousset J, Valette G, Gouders D, et al. Early prediction of survival following induction chemotherapy with DCF (docetaxel, cisplatin, 5-fluorouracil) using FDG PET/CT imaging in patients with locally advanced head and neck squamous cell carcinoma. Eur J Nucl Med Mol Imaging. 2012;39(12):1839-47.

19. Hoang JK, Das SK, Choudhury KR, Yoo DS, Brizel DM. Using FDG-PET to measure early treatment response in head and neck squamous cell carcinoma: quantifying intrinsic variability in order to understand treatment-induced change. AJNR Am J Neuroradiol. 2013;34(7):1428-33.

20. Bittner MI, Wiedenmann N, Bucher S, Hentschel M, Mix M, Weber WA, et al. Exploratory geographical analysis of hypoxic subvolumes using 18F-MISO-PET imaging in patients with head and neck cancer in the course of primary chemoradiotherapy. Radiother Oncol. 2013;108(3):511-6.

21. Abolmaali N, Haase R, Koch A, Zips D, Steinbach J, Baumann M, et al. Two or four hour [(1)(8)F]FMISO-PET in HNSCC. When is the contrast best? Nuklearmedizin Nucl Med. 2011;50(1):22-7.

22. [18F]Fluoromisonidazole. Molecular Imaging and Contrast Agent Database (MICAD). Bethesda (MD)2004.

23. Rajendran JG, Schwartz DL, O'Sullivan J, Peterson LM, Ng P, Scharnhorst J, et al. Tumor hypoxia imaging with [F-18] fluoromisonidazole positron emission tomography in head and neck cancer. Clin Cancer Res. 2006;12(18):5435-41.

24. Kikuchi M, Yamane T, Shinohara S, Fujiwara K, Hori SY, Tona $\mathrm{Y}$, et al. 18F-fluoromisonidazole positron emission tomography before treatment is a predictor of radiotherapy outcome and survival prognosis in patients with head and neck squamous cell carcinoma. Ann Nucl Med. 2011;25(9):625-33.

25. Yamane T, Kikuchi M, Shinohara S, Senda M. Reduction of [(18)F]fluoromisonidazole uptake after neoadjuvant chemotherapy for head and neck squamous cell carcinoma. Mol Imaging Biol. 2011;13(2):227-31.
26. Dirix P, Vandecaveye V, De Keyzer F, Stroobants S, Hermans R, Nuyts $S$. Dose painting in radiotherapy for head and neck squamous cell carcinoma: value of repeated functional imaging with (18)F-FDG PET, (18)F-fluoromisonidazole PET, diffusionweighted MRI, and dynamic contrast-enhanced MRI. J Nucl Med. 2009;50(7):1020-7.

27. Chang JH, Wada M, Anderson NJ, Lim Joon D, Lee ST, Gong SJ, et al. Hypoxia-targeted radiotherapy dose painting for head and neck cancer using (18)F-FMISO PET: a biological modeling study. Acta Oncol. 2013;52(8):1723-9.

28. Choi W, Lee SW, Park SH, Ryu JS, Oh SJ, Im KC, et al. Planning study for available dose of hypoxic tumor volume using fluorine18-labeled fluoromisonidazole positron emission tomography for treatment of the head and neck cancer. Radiother Oncol. 2010;97(2):176-82.

29. Hendrickson K, Phillips M, Smith W, Peterson L, Krohn K, Rajendran J. Hypoxia imaging with [F-18] FMISO-PET in head and neck cancer: potential for guiding intensity modulated radiation therapy in overcoming hypoxia-induced treatment resistance. Radiother Oncol. 2011;101(3):369-75.

30. Eschmann SM, Paulsen F, Reimold M, Dittmann H, Welz S, Reischl G, et al. Prognostic impact of hypoxia imaging with $18 \mathrm{~F}$ misonidazole PET in non-small cell lung cancer and head and neck cancer before radiotherapy. J Nucl Med. 2005;46(2):253-60.

31. Rischin D, Hicks RJ, Fisher R, Binns D, Corry J, Porceddu S, et al. Prognostic significance of $[18 \mathrm{~F}]$-misonidazole positron emission tomography-detected tumor hypoxia in patients with advanced head and neck cancer randomly assigned to chemoradiation with or without tirapazamine: a substudy of Trans-Tasman Radiation Oncology Group Study 98.02. J Clin Oncol. 2006;24(13):2098-104.

32. Zips D, Zophel K, Abolmaali N, Perrin R, Abramyuk A, Haase R, et al. Exploratory prospective trial of hypoxia-specific PET imaging during radiochemotherapy in patients with locally advanced headand-neck cancer. Radiother Oncol. 2012;105(1):21-8.

33. - Mortensen LS, Johansen J, Kallehauge J, Primdahl H, Busk M, Lassen P, et al. FAZA PET/CT hypoxia imaging in patients with squamous cell carcinoma of the head and neck treated with radiotherapy: results from the DAHANCA 24 trial. Radiother Oncol. 2012 Oct;105(1):14-20. One of the larger studies of a nonFDG tracer for head and neck squamous cell carcinoma.

34. Hoshikawa H, Mori T, Kishino T, Yamamoto Y, Inamoto R, Akiyama K, et al. Changes in (18)F-fluorothymidine and (18)Ffluorodeoxyglucose positron emission tomography imaging in patients with head and neck cancer treated with chemoradiotherapy. Ann Nucl Med. 2013;27(4):363-70.

35. Kanda T, Kitajima K, Suenaga Y, Konishi J, Sasaki R, Morimoto $\mathrm{K}$, et al. Value of retrospective image fusion of (1)(8)F-FDG PET and MRI for preoperative staging of head and neck cancer: comparison with PET/CT and contrast-enhanced neck MRI. Eur J Radiol. 2013;82(11):2005-10.

36. Kubiessa K, Purz S, Gawlitza M, Kühn A, Fuchs J, Steinhoff KG, et al. Initial clinical results of simultaneous ${ }^{18} \mathrm{~F}$-FDG PET/MRI in comparison to ${ }^{18} \mathrm{~F}$-FDG PET/CT in patients with head and neck cancer. Eur J Nucl Med Mol Imaging. doi:10.1007/s00259-0132633-2.

37. Chen L, Zhang Z, Kolb HC, Walsh JC, Zhang J, Guan Y. (1)(8)FHX4 hypoxia imaging with PET/CT in head and neck cancer: a comparison with (1)(8)F-FMISO. Nucl Med Commun. 2012;33(10):1096-102.

38. • Hoshikawa H, Kishino T, Mori T, Nishiyama Y, Yamamoto Y, Mori N. The value of 18F-FLT PET for detecting second primary cancers and distant metastases in head and neck cancer patients. Clin Nucl Med. 2013 Aug;38(8):e318-23. Discusses strengths and weaknesses of 18F-FLT for head and neck squamous cell carcinomas. 
39. Hoeben BA, Troost EG, Span PN, van Herpen CM, Bussink J, Oyen WJ, et al. 18F-FLT PET during radiotherapy or chemoradiotherapy in head and neck squamous cell carcinoma is an early predictor of outcome. J Nucl Med. 2013;54(4):532-40.

40. Haerle SK, Fischer DR, Schmid DT, Ahmad N, Huber GF, Buck A. 18F-FET PET/CT in advanced head and neck squamous cell carcinoma: an intra-individual comparison with 18F-FDG PET/ CT. Mol Imaging Biol. 2011;13(5):1036-42.

41. Toubaru S, Yoshikawa K, Ohashi S, Tanimoto K, Hasegawa A, Kawaguchi K, et al. Accuracy of methionine-PET in predicting the efficacy of heavy-particle therapy on primary adenoid cystic carcinomas of the head and neck. Radiat Oncol. 2013;8(1):143.

42. Hasebe M, Yoshikawa K, Ohashi S, Toubaru S, Kawaguchi K, Sato J, et al. A study on the prognostic evaluation of carbon ion radiotherapy for head and neck adenocarcinoma with C-11 methionine PET. Mol Imaging Biol. 2010;12(5):554-62.
43. Ito K, Yokoyama J, Kubota K, Morooka M. Comparison of 18FFDG and 11C-choline PET/CT for detecting recurrences in patients with nonsquamous cell head and neck malignancies. Nucl Med Commun. 2010;31(11):931-7.

44. Ito K, Yokoyama J, Kubota K, Morooka M, Shiibashi M, Matsuda H. 18F-FDG versus 11C-choline PET/CT for the imaging of advanced head and neck cancer after combined intra-arterial chemotherapy and radiotherapy: the time period during which PET/CT can reliably detect non-recurrence. Eur J Nucl Med Mol Imaging. 2010;37(7):1318-27.

45. Beer AJ, Grosu AL, Carlsen J, Kolk A, Sarbia M, Stangier I, et al. [18F]galacto-RGD positron emission tomography for imaging of alphavbeta3 expression on the neovasculature in patients with squamous cell carcinoma of the head and neck. Clin Cancer Res. 2007;13(22 Pt 1):6610-6. 